\title{
EDUCATION
}

\section{The role of postgraduate dental deans}

\author{
C. D. Franklin ${ }^{1}$ and D. G. Smith ${ }^{2}$
}

\section{"One of the attractions of the job is taking on the responsibility for ensuring that the next generation of doctors and dentists is properly taught and prepared"}

\author{
${ }^{1}$ Dr CD Franklin, Vice Chair, \\ COPDEND, University of \\ Sheffield, Dept of Oral Pathology \\ School of Clinical Dentistry, \\ Claremont Crescent, Sheffield, \\ UK. ${ }^{2}$ David G Smith, \\ Postgraduate Dental Dean, Chair \\ of COPDEND, Postgraduate \\ Institute for Medicine \& \\ Dentistry, University of \\ Newcastle, 10-12 Framlington \\ Place, Newcastle upon Tyne. \\ Corerespondence to: \\ Dr C D Franklin. \\ Email:c.franklin@sheffield.ac.uk
}

Postgraduate Dental Deans commission and manage the delivery of postgraduate dental and medical education and training for dental practitioners. They are charged with developing and quality assuring opportunities for trainees in primary and secondary care so that they can reach their full potential, and must work with local organisations to ensure that sufficient training places are available to meet the future needs of the NHS. Postgraduate dental deans influence training opportunities and standards in NHS Trusts as well as dental vocational training practices. They also play a role in developing national policies on postgraduate dental education and implement new initiatives. Their roles cover modernising dental careers, national and international recruitment and retention in primary and secondary care. They are involved in leading the development of the dental workforce, including professions complementary to dentistry as well as managing the provision and quality assurance of CPD for general practitioners. They also provide support for doctors and dentists facing difficult situations

\section{INTRODUCTION}

The principal role of a postgraduate dental deans (PDDs) is to commission and manage the delivery of postgraduate dental and medical education and training for dental practitioners. Their role is poorly described, not well understood, and yet their work has a direct impact on most dentists in their deaneries. The job is influential and postgraduate deans must have strong leadership and political skills. They also need to be firm negotiators, persuaders and problem solvers, and they must be able to implement change. Pace of change within the NHS over the past decade has been inexorable and PDDs have been at the forefront of facilitating dentistry's interface with new structures and processes.

PDDs are charged with developing opportunities for all trainees to reach their full potential with the available resources. They must work with local organisations to ensure that sufficient training places are available to meet the future needs of the NHS and that recruitment to those places is rigorous and fair. Postgraduate dental deans influence training opportunities, places in which to train, rotational arrangements and standards in NHS Trusts as well as dental vocational training practices. They also play a role in developing national policies on postgraduate dental education and implementing new initiatives at the coalface.

Managing and delivering postgraduate dental and medical training represents the vast bulk of the work of deans and their staff. This involves recruitment, assessment, remediation, educator development (ie VT and consultant trainers as well as dental tutors and advisers) and the quality assurance of trust and general practice-based education.
PDDs will be expected to lead in several areas such as:

- Leading the implementation of Modernising Medical and Dental Careers;

- Supporting the work of the NHS to create more consultant and primary care dental staff posts (including through international recruitment) and help with the expansion of trainees;

- Provision of induction courses for overseas dentists

- Supporting the NHS to implement EWTD for trainee doctors and dentists;

- Leading the development of the dental workforce, including professions complementary to dentistry;

- CPD for general practitioners;

- Support for doctors and dentists in difficulties.

By 2008, PDDs will be involved in other areas of work such as increasing the dental workforce. In addition to the roles listed above there are a number of areas in which PDDs may be expected to play a greater role to the overall benefit of the NHS. For example:

- Support for dental non-consultant career grade staff (staff grades, associate specialists, trust grades, etc);

- CPD for non-training grades and PCDs generally;

- Specialist training for PCDs;

- And inter-professional learning generally.

It is likely that support will be needed for post registration PCDs and the ways in which PDDs and their teams can work with other workforce colleagues on the development of new clinical roles.

Postgraduate dental deans are accountable to the Department of Health, currently through Strategic Health Authorities, for delivering education and managing a substantial budget; this includes 
funding for administrative and educational staffing costs as well as funding 50\% of the basic salary of SHOs and 100\% of the salaries of specialist registrar (SpRs) in the dental specialties. In addition, PDDs receive funding for the training of vocational dental practitioners (VDPs) and administration of dental vocational training; they also receive a per capita amount for each NHS primary care dentist in their deanery to provide MPET ${ }^{\dagger}$ funded (Section 63) courses. PDDs may also have academic accountability to their respective universities in respect of the link between the undergraduate dental course and vocational training.

PDDs must ensure that the training places and programmes they commission meet the quality standards set by the Faculties of the Royal Colleges, Committees for Vocational Training/DVTA, by the GDC and possibly the Professional Medical Education Training Board (PMETB). They do this in the hospital environment through placing and monitoring educational contracts with Trusts through a network of hospital tutors and educational supervisors working with SHOs and Training Programme Directors for the dental specialties. In primary care, the quality agenda is addressed through the appointment and work of VT Scheme Advisers and through training agreements with VT training practices and VDPs. In addition, the CPD programmes and courses delivered by Postgraduate Dental Tutors, Regional Advisers in Clinical Community Dentistry and other course organisers in conjunction with postgraduate centre managers must be quality assured and are open to scrutiny by the GDC. There are also Regional Advisers for Retaining and Returning who, in collaboration with the above networks, develop opportunities and support for those taking career breaks, refugees and asylum seekers.

\section{MONITORING STANDARDS}

The deaneries manage higher specialist training through specialty training committees that bring together the Royal Colleges' regional and specialty advisors, the training programme directors, the consultant trainers and the postgraduate dental deans and their support team.

The PDD is engaged at all stages of the trainee's pathway, either directly (eg for specialist registrars) or indirectly through contracting to provide quality assured processes (eg for SHOs, VDPs). Deans are responsible for:

- Recruitment and selection of specialist registrars;

- Maintaining databases of all dentists in training;

- Issuing national training numbers to SpR trainees to legitimise training;

- Overseeing the annual records of in-training assessments exercise for trainees;

- Arranging reviews and appeals, and organising remedial training for trainees, if required;

- Confirming to the appropriate pecialist advisory Committee of the Joint Committee for Specialist Training in Dentistry or (in the case of oral and maxillofacial surgery) the Joint Committee for Higher Surgical Training, that hospital and dental public health SpR trainees have completed their programme of training and are ready for the award of the certificate of completion of specialist training that allows entry to the GDC specialist lists.

- And helping doctors and dentists with special needs or difficulties.

In addition, PDDs contribute to regional workforce planning processes through workforce development directorates of strategic health authorities and via national workforce advisory groups. Several deans also do an important national workforce monitoring role as Lead Dean (see below).

The PDD has to manage the team that helps to carry out the work of the deanery. The size of the team depends on the size of their patch and the number of trainees and dental practitioners. The team will usually include one or more associate deans and a business manager together with a number of administrators and clerical staff. The dean must also maintain a good relationship with the clinical and dental tutors, advisers and training programme directors that are appointed and who are key players in developing education on the ground in each NHS acute or community trust or training practice.

PDDs meet on a regular basis at the Committee of Postgraduate Dental Deans UK (COPDEND); this provides a forum to discuss issues, share best practice and agree a consistent and equitable approach to training. The Conference of Postgraduate Dental Education UK (COPDEUK) comprises PDDs and other stakeholders in postgraduate dental education. The conference meets twice a year and hosts an education meeting in the morning and a business meeting in the afternoon. Details are available about this and other postgraduate dental education and training issues on the COPDEND website (www.copdend.org). Links to deaneries can also be found on this site.

\section{EMPLOYMENT}

Postgraduate deans have usually been employed jointly by universities and one or more strategic health authorities. They are paid consultant rates and are eligible for merit awards. They are appointed from the ranks of consultants and dentists who work in primary care and who have a track record of holding appointments with responsibility for education and management.

Some recent reports have suggested that there would be merit in the development of a specialty of medical/dental education. Such a proposal would entail the agreement of a framework of skills and competencies and a system to establish standards and test eligibility to be designated as a specialist in this field. This would allow employment as a consultant in the specialty, for most as a dual specialty with primary care or secondary care specialty. It may encourage succession planning and career progression for the role of the PPD but also be relevant for other aspects of medical and dental education and training.

\section{RELATIONSHIPS}

PGDDs are part of a broader Deanery team usually led by the Postgraduate Medical Dean, and incorporating the Director of General (medical) Practice Education, a variety of associate deans (with specific 
portfolios) and business managers. PGDDs interact with a large number of individuals and organisations (see Fig 1). Deans therefore sit on many local, region$\mathrm{al}$ and national committees often acting as representatives of COPDEND. In particular, PGDDs are regularly in touch with the four UK CDOs and the Departments of Health with regard to the full scope of educational and training issues including vocational training and CPD initiatives. The latter includes promoting education on child protection, smoking cessation and e-learning projects such as those released in 2004 on cross-infection control and endodontics. Further projects will be released during 2005. PGDDs are also working with the Faculties of the Royal Colleges on SHO curriculum and competencies. In Scotland, there have been different developments including formative and summative assessment of vocational training, and SHO competencies using longitudinal evaluation of performance.

\section{WORK OF DEANS}

Apart from strategic development, administration and committee work, the day-to-day work of deans includes providing career counselling and mentoring of trainees, whether it be VDPs or SHOs and SpRs in the dental specialties, overseas trainees, asylum seekers, refugees or supporting those in difficulty such as poorly performing dentists. Recently deans have been involved in the international recruitment of European and overseas dentists as well as providing induction programmes for them.

PGDDs disseminate information and manage deanery work through a number of regional education committees such as those for VT and CPD as well as overarching committees with wide representation from stakeholders in postgraduate dental education. There are also specialty training committees to manage the training of SpRs in the dental specialties. The latter committees are normally involved in managing study leave, annual assessments, organising training rotations and quality assuring training as well as dealing with occasional failing trainees. Committees also hear appeals from trainees over various issues. In today's litigious society deans are increasingly likely to be involved in tribunals when appeals fail to resolve issues or they may even find themselves on the receiving end of a writ.

Much of the work done in deaneries involves essential quality assurance of various processes. The bureaucracy that this creates often seems burdensome to our trainer colleagues in both primary and secondary care. However, in the interests of objectivity, fairness and transparency for all concerned in disputes, we rely on such thorough information and documentation when things go wrong in training. Tribunals may uphold appeals against the judgement of poor progress in training because of inadequacies in the paperwork and process.

In the constant clinical and educational quest for 'doing the right things and doing them right', postgraduate dental deans engage in evaluation, research and development as allowed by time and resource. Development of e-learning and portfolios, the effectiveness

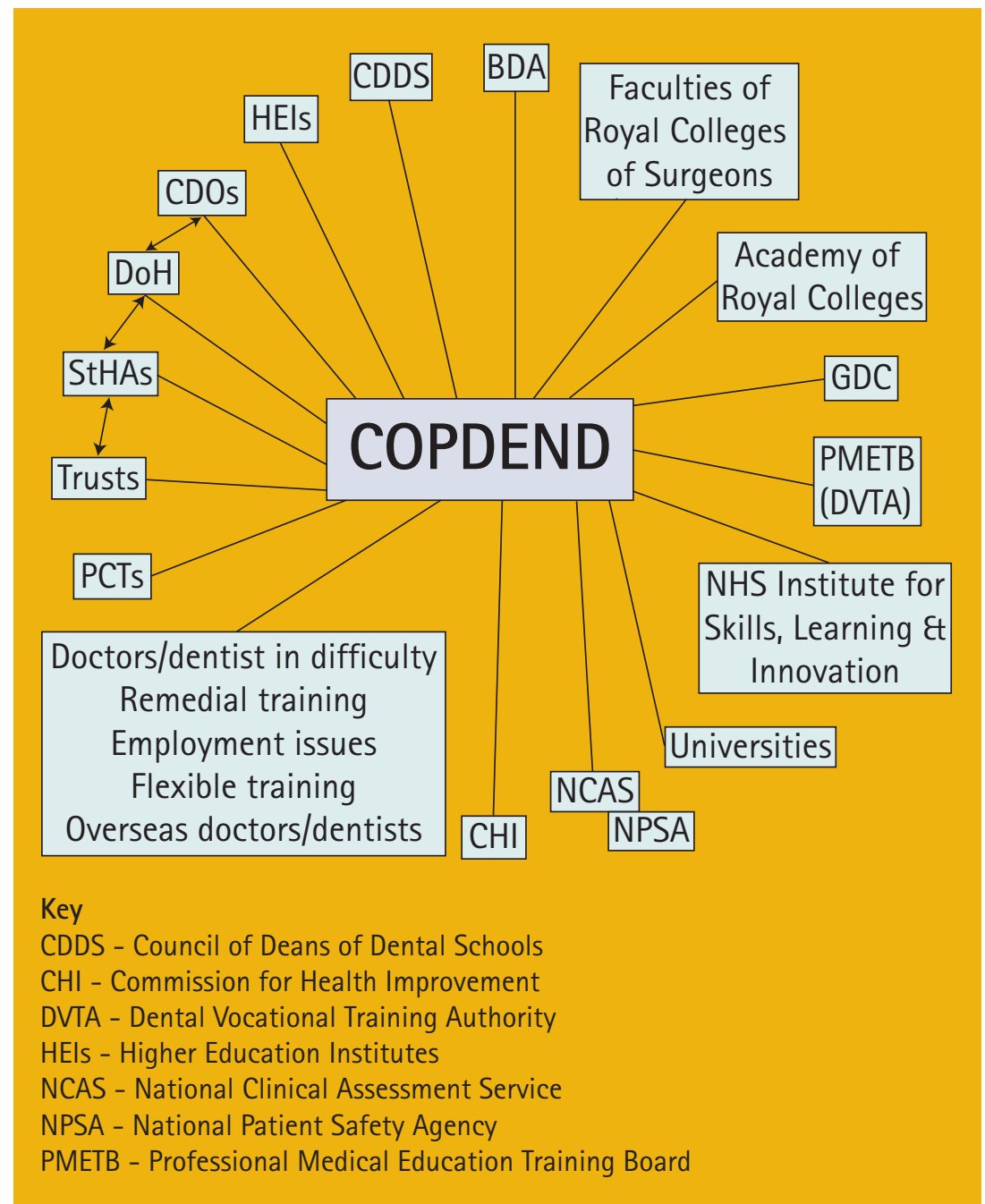

of CPD, and recruitment and retaining processes as well as assessment tools to test competence have all been the subject of deanery work in the UK.

\section{THE ROLE OF A LEAD DEAN}

Some PGDDs are responsible for taking a national role in developing and managing a particular specialty, or group of specialties; this is the so-called Lead Dean role. Roles for the Lead Dean in England include being manager, adviser, honest broker, and representative.

The responsibilities of the Lead Dean for any specialty are to:

- Contribute to workforce planning in the specialty and relevant sub-specialties, including recommendations on the distribution and allocation of National Training Numbers (NTNs);

- Represent PDDs and Deaneries at appropriate committees or organisations, including speaking at specialty meetings;

- Promote the highest standards of quality assured medical and dental education and training;

- Work with the relevant College or Faculty to develop and advance the specialty;

- Contribute to national policy and its implementation;

- Act as a conduit for information, eg about educational developments;

- And act as a focal point for advice. 


\section{WORKFORCE PLANNING}

It is the Lead Dean's responsibility, in conjunction with the Department of Health Workforce Review Team (WRT) in England, to manage NTNs for specialties that are increasing or decreasing, in accordance with national policy. The Lead Dean 'holds' the stock of NTNs and distributes these to PDDs who wish to obtain extra numbers when research or flexible trainees are appointed to SpR posts. NTNs that are not in active use must be 'returned' to the Lead Dean. Monitoring and data collection is undertaken systematically by the WRT. In expanding specialties, the Lead Dean helps coordinate and monitor the distribution and implementation of centrally funded and locally funded NTNs, in conjunction with the WRT in England. The Lead Dean brokers the redistribution of NTNs that cannot be used by those Deaneries to which they were originally distributed. In general, Lead Deans link with arrangements for national workforce planning in relation to what is happening in service planning as well as with the WRT, Colleges and Faculties.

\section{REPRESENTING POSTGRADUATE DEANS}

The Lead Dean represents his/her colleagues on appropriate Royal College and Higher Specialist Training Committees with reference to education and training issues and workforce planning. Where appropriate, this extends to other committees or bodies, such as specialist societies who may deal with education and training and related quality assurance matters in the specialty. It is the responsibility of Lead Deans to not only work with but challenge Royal Colleges and specialist societies where appropriate, for example, reconciling the approach to training and the numbers of doctors and dentists required for service delivery.

\section{DEVELOPING AND ADVANCING SPECIALTIES}

Lead Deans champion and support the cause of quality assured education and training in the specialties for which they are responsible and should take a UKwide perspective. Examples include the development of educational portfolios, handling issues relating to accreditation, advising on relevant issues relating to academic medical and dental careers, and the development of new examinations and approaches to assessment.

It is particularly important that the Lead Dean supports a pro-active approach to the changes that will be needed to implement within the specialty and that there is an appropriate focus on the establishment of explicit curriculum and related valid and reliable assessment systems.

\section{CONTRIBUTION TO NATIONAL POLICY}

To support effective workforce planning, Lead Deans have an important role in contributing to the formulation of policy by the Department of Health and in implementing its recommendations. This is achieved by participating, in England, in the WRT specialty reviews to contribute advice on training capacities and the implications of changes.

\section{FOCAL POINT FOR ADVICE}

Lead Deans are conduits for the exchange of information and concerns in both directions between postgraduate deans and various stakeholders. The latter include the health services and the Departments of Health; the Royal Colleges, their faculties and higher training committees and others such as specialist societies.

Through gaining particularly deep insights, and keeping abreast of specialty specific issues, a Lead Dean can act as a focal point for responding to queries, questions and requests for advice from a range of sources (including colleague Postgraduate Deans, their Associates and other colleagues; specialty Training Programme Directors; Royal Colleges and Faculties, and their Advisers or Tutors locally, and Strategic Health Authorities).

While providing advice for trainees with difficulties is normally the responsibility of postgraduate deans and their staff, locally, there are rare occasions when Lead Deans may be asked for advice in confidence outside their local area.

\section{ATTRACTION OF THE ROLE OF POSTGRADUATE DENTAL DEAN}

Professor Peter Hill, formerly chair of the Committee of Postgraduate Medical Deans (COPMeD), probably spoke for most of his dean colleagues when he told Hospital Doctor magazine: "One of the attractions of the job is taking on the responsibility for ensuring that the next generation of doctors and dentists is properly taught and prepared. It is also a challenge to be able to shape policy at the centre. You have to be a credible clinician and you have to have credibility in education, you also have to be able to communicate to get people on board, and you need a certain amount of political nous. You can often find yourself facing both ways - you have to manage things on the ground and also manage people at the top. You end up in the middle, between the conflicting demands of training and NHS service requirements. It's a constant battle to keep education and training on the agenda, both nationally and locally."

WB Yeats' oft-quoted maxim "education is about lighting fires, not filling pails" probably encapsulates the conviction which drives most people who are significantly engaged in postgraduate dental education. It is certainly true as far as PGDDs are concerned and accounts for the continuing enthusiasm of colleagues despite the burgeoning agenda. Recruitment of PGDDs is frequently, but not always, from colleagues in primary or secondary dental care who are actively involved in some aspect of postgraduate dental education. For those who aspire to appointments such as tutors, advisers, associate PDDs, it will be worthwhile investigating what further qualifications might be needed and how personal development and leadership training would enhance appointment prospects. Existing colleagues currently in these various roles in deaneries will be happy to provide assistance. 